\title{
Similaridade de Papéis Entre Professor-Tutor e Aluno em Cursos a Distância
}

\section{Similarity in the Roles of Tutoring Teachers and Students in Distance Courses}

\begin{abstract}
Resumo: Esse estudo teve como objetivo investigar a similaridade de papéis desempenhados por professor-tutor e aluno em contextos a distância. A pesquisa foi realizada com 18 alunos do terceiro semestre do curso de Graduação semipresencial em Letras-Português da Universidade Federal do Ceará, uma parceria com a Universidade Aberta do Brasil, no semestre $2008 / 2$. Utilizou-se como método de pesquisa o etnográfico e os princípios da etnografia virtual. Os resultados obtidos validaram os papéis já encontrados na literatura e possibilitaram elencar outros que ainda não estavam propostos. Esses papéis se manifestaram especificamente nos espaços formais de aprendizagem.

Palavras-Chaves: Similaridade de papéis. Educação a distância. Comunidade Virtual de Aprendizagem Formal.
\end{abstract}

Abstracts: This study's objective is to investigate the similarity in roles performed by the tutoring teachers and students in a distance course context. The research was performed with 18 3rd semester undergrad students in semi-presential mode at Languages - Portuguese in a Federal University of Ceara, a partnership with the Open University of Brazil (Universidade Aberta do Brasil), on semester $2008 / 2$. The ethnographic method was chosen along with the principles of virtual ethnography. The obtained results validated the roles which were already found in literature and made it possible to expose some others which hadn't been proposed yet. These roles were specifically manifested in formal spaces of learning.

Keywords: Similarity in roles. Distance Education. Virtual Community of Formal Learning.

VENTURA, Paula Patrícia Barbosa. Similaridade de Papéis Entre Professor-Tutor e Aluno em Cursos a Distância. Informática na Educação: teoria e prática, Porto Alegre, v. 18, n. 1, p. 115-133, jan./jun. 2015.

\author{
Paula Patrícia Barbosa Ventura \\ Universidade Federal do Ceará
}

\section{Introdução}

A Educação a Distância (EaD) é uma modalidade de educação que requer um redimensionamento das práticas educativas e não significa uma reprodução do que se realiza na educação presencial. Segundo Moran (2006, p. 43), naquela modalidade "os papéis do professor se multiplicam, diferenciam-se e complementam-se, exigindo uma grande capacidade de adaptação e criatividade diante de novas situações, propostas, atividades". Essa complexidade de papéis desempenhados pelo docente na EaD, configura o que Mill (2010) e Cerny e Lapa (2012) denominam de polidocência e professor coletivo, respectivamente.

No entanto, não se deve pensar somente na figura docente, uma vez que professor e aluno estão inseridos no mesmo processo, o que justifica o emprego da expressão educa- 
ção à distância e não ensino a distância, pois nesta última a ênfase é dada ao ensino e ao professor, enquanto na primeira expressão, a ênfase é dada tanto ao professor quanto ao aluno recaindo no binômio ensino-aprendizagem, podendo-se pensar na relação entre docente e discente e destes entre si, não afirmando, porém, que um termo (ensino) implicará necessariamente no outro (aprendizagem).

Diversos trabalhos abordam os papéis do professor online (CARVALHO, 2007, MOORE; KEARSLEY, 2006, SILVA; ALVES, 2005, ALVARIÑO, 2004, MACHADO; MACHADO, 2004, SOUZA et al., 2004, MARTINS, 2003, PALLOFF; PRATT, 2002, EMERENCIANO; SOUSA; FREITAS, 2001, ARREDONDO, 1998), bem como do aluno (GONÇALVES, 2006, MOORE; KEARSLEY, 2006, SILVA; ALVES, 2005, PALLOFF; PRATT, 2002, 2004), mas o que se percebe são apenas recomendações sobre o perfil, as competências e as habilidades esperadas. Outras vezes confundem papéis com denominação /nomenclatura (PRADO; ALMEIDA, 2003). Por um lado, encontram-se trabalhos meramente teóricos e, por outro, estudos que elencam separadamente os papéis do professor-tutor e do aluno (SILVA, 2013, CERNY; LAPA, 2012, SCHILLER; LAPA; CERNY, 2011, TORRES, 2007, SARMET, 2003).

A partir dos resultados de uma pesquisa realizada com alunos num curso a distância ${ }^{1}$, uma das categorias estabelecidas foram os papéis desempenhados por professor-tutor ${ }^{2}$ e alunos, possibilitando refletir criticamente a similaridade entre eles e o que a literatura

\footnotetext{
1 A pesquisa é parte da dissertação de mestrado da autora deste artigo (VENTURA, 2009). Em especial, a autora agradece aos professores-orientadores José Aires de Castro Filho e Eduardo Santos Junqueira Rodrigues pelas contribuições ao longo da pesquisa.

2 A expressão professor-tutor é utilizada para designar o tutor a distância, conforme detalhado na seção 3.
}

aborda como sendo esperado ou não às atribuições desses atores no processo de ensino e aprendizagem à distância. O termo similaridade se refere aos papéis semelhantes e que foram exercidos pelos participantes em situações formais de ensino e aprendizagem. Entende-se por situações formais de ensino e aprendizagem, os momentos em que o professor explica o conteúdo, faz a mediação nos fóruns de conteúdo e bate-papo, quando os alunos apresentam trabalho em grupo e em outros momentos detalhados neste artigo.

Para tanto, esse artigo está dividido em quatro seções. A princípio, apresentam-se os múltiplos papéis que o professor-tutor e o aluno podem assumir. Posteriormente, propõe-se o objeto de estudo e a metodologia do trabalho. Os resultados discutem quais os papéis foram efetivamente encontrados em situações formais de ensino e aprendizagem. Ao final, são apresentadas as considerações do estudo e algumas sugestões para pesquisas posteriores.

\section{Os Múltiplos Papéis dos Atores So- ciais em Contextos a Distância}

Giddens (2005) argumenta que a ideia do papel social foi inspirada no teatro, referindo-se aos papéis desempenhados pelos atores em uma produção teatral. Para o autor, em toda sociedade, os indivíduos desempenham uma série de papéis sociais diferentes, conforme a diversidade de contextos de suas atividades.

Os papéis podem ser definidos como um conjunto de comportamentos esperados, desempenhados pelos indivíduos (BRYM et al., 2006). Em situações de ensino e aprendizagem, esses papéis são atribuídos ao professor e aluno. Niskier (1999) elenca que os papéis 
do professor online são: comentar os trabaIhos dos alunos; corrigir as avaliações dos alunos; ajudá-los a compreender os materiais do curso através de discussões e explicações; responder as questões sobre a instituição; ajudar os alunos a planejar seus trabalhos; organizar círculos de estudo; fornecer informações por telefone e e-mail; supervisionar trabalhos práticos e projetos; atualizar informações sobre o progresso dos estudantes; fornecer feedback aos coordenadores sobre os materiais dos cursos e as dificuldades dos estudantes, e servir de intermediário entre a instituição e os alunos.

Para Alonso e Alegretti (2003), a presença do professor contribui para fazer dos cursos online um ambiente rico e dinâmico. Sua presença pode ser atribuída como um de seus papéis e serve para encorajar a interação dos membros em uma comunidade de aprendizagem, embora nem toda comunidade virtual de aprendizagem (CVA) seja mediada por um professor-tutor. A presença referida não é a física, mas a de estar sempre atento e disponível aos alunos, cabendo-lhe incentivar, problematizar e mediar as discussões, proporcionando feedback às dúvidas e aos questionamentos surgidos. Verifica-se ainda que não só a figura do professor-tutor é essencial para instigar a interação entre os alunos em um curso a distância, mas alguém que seja capaz de assumir esse papel de modo que todos se sintam motivados a participarem e a se sentirem membros de uma CVA, sendo possível identificar pessoas que têm uma participação mais ativa e frequente nas discussões.

Kenski (2003) enfatiza que o professor no ambiente virtual deve atuar como coordenador o tempo inteiro porque é ele quem constrói, articula e viabiliza estruturalmente o curso, além de propor leituras e atividades para manter o funcionamento do curso em andamento. Outro papel que a autora destaca é o de pessoa, o que estaria relacionado ao envolvimento e acolhimento dos alunos entre si. Visto de outra forma, esse papel de pessoa estaria relacionado ao papel social do professor, o que não necessariamente teria relação com as atividades formais do curso, e sim papéis como o de amigo, conselheiro, parceiro e eterno ouvinte, por exemplo.

Complementando o papel de pessoa, Arrendondo (1998) enfatiza que um dos papéis do professor-tutor é o de oferecer possibilidades permanentes de diálogo, saber ouvir, ser empático e manter uma atitude de cooperação, o que não necessariamente estaria ligado ao nível cognitivo. Este autor cita outros papéis: atuar como mediador; conhecer a realidade de seus alunos em todas as dimensões (pessoal, social, familiar, escolar); oferecer experiências de melhoria de qualidade de vida, de participação, de tomada de consciência, de elaboração dos próprios projetos de vida; demonstrar competência individual e de equipe para analisar realidades, formular planos de ação coerentes com os resultados de análises e de avaliação etc.; identificar suas capacidades e limitações para atuar de forma realista com visão de superação; manter uma atitude reflexiva e crítica sobre a teoria e a prática educativa; possibilitar a comunicação entre os diferentes níveis, de pessoas, de coletivos etc. Diante dos papéis elencados por Kenski (2003) e Arrendondo (1998), os quais destacam o lado social e humano do professor-tutor, verifica-se que este assume não apenas competências de um mediador pedagógico, mas também de um mediador social. Esta expressão pode ser conceituada como aquele professor (no caso, o tutor) capaz de se relacionar e estabelecer vínculos 
com a turma, uma vez que não é suficiente ter domínio do conteúdo e transpô-los didaticamente, mas sim ser o elemento dinamizador e propiciador das relações sociais entre os alunos.

Em discussão semelhante, Silva (2013) e Cerny e Lapa (2012) desenvolveram um estudo empírico, no qual se confirmou que os papéis desempenhados pelos professores-tutores, são similares aos já discutidos anteriormente. Em seu estudo, Silva (2013) cita Mill (2010), ao explicitar que os papéis entre os docentes na EaD, por vezes, confundem-se, ratificando a importância de um trabalho coletivo, uma vez que seu estudo não focou na análise isolada da figura do professor-autor/ conteudista, professor-tutor e outros participantes da docência, mas sim da docência em seu conjunto. Ainda assim, destaca-se que o professor-tutor participa da docência e acompanha de modo mais próximo e direto o aluno influenciando direta ou indiretamente no processo pedagógico do curso.

Cerny e Lapa (2012) destacam como sendo papéis fundamentais ao exercício da tutoria, o acompanhamento dos discentes em seu próprio processo de aprendizagem e a mediação pedagógica entre professores, alunos e instituição. A pesquisa destes autores mostrou também, a execução de estratégias pedagógicas elaboradas pelo professor-autor (conteudista da disciplina), assim como a orientação e esclarecimento de dúvidas acerca de questões específicas do conteúdo como importantes papéis exercidos pelos professores-tutores.

Assim como o papel do professor tem sua importância na Educação a Distância via Internet, o aluno também ocupa lugar de destaque e tem papéis a desempenhar (GONÇALVES, 2006, MOORE; KEARSLEY, 2006, SILVA; ALVES, 2005, PALLOFF; PRATT, 2002, 2004).
Palloff e Pratt (2002) destacam que os alunos têm o papel de colaborar, produzir conhecimento e gerenciar o processo, o que inclui ser

[...] facilitador da discussão; observador do processo, comentando a dinâmica do grupo; comentarista do conteúdo, resumindo o que foi aprendido pelo grupo durante a semana anterior; líder de equipe com ou sem a responsabilidade adicional de avaliar o trabalho dos outros participantes e apresentador de determinado tópico, livro ou área de interesse (PALLOFF; PRATT, 2002, p. 152).

Reforçando esses papéis, Guimarães (2012, p. 128) enfatiza que "o aprendente assume um papel central no processo de aprendizagem e não pode ser tratado como um receptor passivo da informação, devendo necessariamente ser incluído como um autor, um cocriador, um avaliador e comentador crítico". O que acontece muitas vezes, é que esses papéis são atribuídos somente ao professor como sendo o único responsável pelo processo de ensinar e aprender, mas acredita-se que uma abordagem centrada no aluno e que não exclua a presença do professor seja fundamental para que ocorram as trocas comunicativas e o intercâmbio de ideias. Destarte, o aluno que escolhe realizar seus estudos nessa modalidade de educação deve ter algum conhecimento de suas vantagens e desvantagens, bem como adquirir autonomia, ser disciplinado, estabelecer horários de estudo e de participação dos encontros síncronos, bem como cumprir os prazos das atividades, o que torna o professor um parceiro, colaborador e mediador do processo.

Para que o aluno online desempenhe os papéis descritos, é importante, primeiramente, que ele possua algumas habilidades pessoais e requisitos tecnológicos, elencados por 
Borba et al. (2007), Moore e Kearsley (2006) e Palloff e Pratt (2004). As habilidades pessoais do aluno virtual são: automotivação, capacidade de adaptação a novas situações, organização do tempo e disciplina e saber se comunicar de forma escrita. Os requisitos tecnológicos se referem ao acesso à Internet e considerar a tecnologia como ferramenta de apoio.

Um papel já citado por Pallof e Pratt (2002) e bem enfatizado por Miranda e Osório (2008) é a liderança, considerado elemento fundamental para o desenvolvimento e durabilidade numa comunidade de prática. Os autores enfatizam que o líder deve fazer parte da comunidade cujos interesses sejam semelhantes ao dos outros participantes e suas características passam pela capacidade de gerir, coordenar, orientar, estabelecer normas de funcionamento e ajudar na tomada de decisões. Para tanto, Miranda e Osório argumentam que a liderança em contextos virtuais

[...] pressupõe o desenho de um contexto agradável e apropriado ao desenvolvimento das interacções, preparação do contexto face às reais necessidades do grupo, gestão dos recursos, perspectivas futuras e inovadoras para o contínuo desenvolvimento da comunidade (MIRANDA; OSÓRIO, 2008, p. 2).

Ou seja, na visão destes autores, a liderança é considerada o elemento-chave, embora não seja o único, para o bom desenvolvimento de um espaço online, das interações e construção do conhecimento. Ainda que não especifiquem se esse papel é atribuído ao docente ou discente, é possível inferir que ambos possam assumi-lo.

Ao discutir as comunidades cooperativas de aprendizagem em rede, Gonçalves (2006) destaca que os alunos devem ajudar-se, dis- cutir entre si as questões propostas, avaliar o que sabem e o que não sabem, e colaborar na "superação compartilhada de problemas, o que enseja a aquisição de habilidades, dentre as quais a de intercâmbio de ideias, a negociação de posicionamentos distintos e a resolução de conflitos" (GONÇALVES, 2006, p. 55). Ainda que seu foco não seja os papéis desempenhados pelo discente, Gonçalves (2006) frisa que a importância do aluno exercer tais papéis, os quais a autora (op.cit) considera premissas fundamentais no trabaIho cooperativo.

Alguns papéis atribuídos ao professor-tutor (NISKIER, 1999) podem também ser papéis do aluno, como: comentar os trabalhos dos alunos; ajudá-los a compreender os materiais do curso através de discussões e explicações; organizar círculos de estudo e fornecer informações por telefone e e-mail, não sendo, portanto, papéis exclusivos do professor-tutor. Para tanto, os papéis desempenhados por docente e discente se relacionam entre si, pois em alguns momentos ambos assumem papéis recíprocos. Todavia, não se deve enxergar como papéis isolados e independentes, uma vez que professor e aluno fazem parte do mesmo processo. Ainda assim, não são papéis prontos e acabados, mas sim construídos e aperfeiçoados/ (re)significados e (re)definidos ao longo da prática educativa, seja ela presencial ou a distância.

O surgimento de vários papéis tanto por parte do professor-tutor quanto do aluno indica que a comunidade está se desenvolvendo, os participantes estão indo ao encontro dos outros e tomando consciência do desenvolvimento do curso (PALLOFF; PRATT, 2002).

A metodologia do estudo é apresentada a seguir. 


\section{Metodologia}

O estudo foi desenvolvido no semestre 2008/2, em uma turma de Graduação semipresencial em Letras-Português da Universidade Federal do Ceará (UFC) realizado em parceria com a Universidade Aberta do Brasil (UAB). Participaram da pesquisa, os 18 alunos regularmente matriculados no terceiro semestre do curso e seus respectivos professores-tutores ${ }^{3}$. O período de investigação correspondeu a duas disciplinas: Língua Portuguesa: Frase e Latim II: Língua e Cultura. Cada disciplina contou com uma carga horária de 64 horas (16 horas presenciais distribuídas em quatro encontros e 48 horas, que aconteceram através do ambiente virtual de aprendizagem SOLAR ${ }^{4}$ ). Esta turma foi escoIhida porque o (a) pesquisador (a) atuou no semestre anterior à pesquisa, em 2008.1, numa das disciplinas do curso como professor (a) - tutor (a), o que provavelmente ajudou a sua inserção e aceitação para a realização da pesquisa. A escolha das disciplinas se deu por serem disciplinas obrigatórias e referentes à área específica do curso, por isso a exigência dos alunos estarem regularmente matriculados.

A metodologia de pesquisa teve caráter predominantemente qualitativo sendo utilizado o método etnográfico (BOGDAN; BIKLEN, 1994) e os princípios da etnografia virtual (HINE, 2004) na coleta e análise dos dados. Para a coleta de dados, foram utilizadas en-

\footnotetext{
${ }^{3}$ No contexto da pesquisa e de acordo com a gestão do sistema da UAB - UFC, o professor-tutor ou tutor a distância, não necessariamente faz parte do quadro efetivo da universidade, mas tem formação em nível superior. Preferencialmente, deve participar do planejamento da disciplina, além de realizar a interface com o aluno, acompanhando-o nas atividades a distância e se deslocar aos polos para ministrar aulas por ocasião dos encontros presenciais. Executa metodologias de avaliação, aplica e corrige as provas.

${ }^{4}$ Disponível no site http://www.solar.virtual.ufc.br
}

trevistas e observações presenciais e virtuais. As observações foram referentes às anotações do diário de campo, dois fóruns de discussão (os que tiveram o maior número de participações) e três bate-papos.

A partir da observação dos eventos (diário de campo, entrevistas, bate-papos ${ }^{5}$ e fóruns), elencaram-se as categorias de análise, com o intuito de construir diálogos e estabelecer relações entre os eventos e o referencial teórico, permitindo lidar com o campo complexo das trocas simbólicas e das interações. Em seguida, as categorias propostas foram agrupadas em categorias maiores. Nessa etapa, foi feita a triangulação dos dados (MOREIRA; CALEFFE, 2006), na qual se estabeleceram as relações existentes entre os dados, verificando os pontos de convergência, divergência e regularidades. Por fim, buscou-se investigar quais os papéis desempenhados por professor-tutor e alunos em situações formais de ensino e aprendizagem. Os resultados da análise são apresentados na próxima seção.

\section{Análise e Discussão dos Resulta- dos}

A partir dos dados, os papéis desempenhados por professor-tutor e alunos foram divididos em papéis esperados e não-esperados. Esperados porque há uma expectativa que o indivíduo desempenhe um papel ao assumir determinada posição social. E não-esperados quando determinados papéis não são esperados e o indivíduo desempenha ao assumir uma posição social que não necessariamente exija aquele comportamento.

\footnotetext{
${ }^{5}$ Foram três bate-papos, cada um foi dividido em duas turmas devido a quantidade de alunos.
} 
Os papéis foram definidos como os diferentes comportamentos que o indivíduo desempenhou em situações específicas. Os papéis esperados num ambiente de aprendizagem foram também chamados de papéis tradicionais ou pré-determinados. Tanto o aluno quanto o professor-tutor desempenharam papéis diversos, conforme será mostrado posteriormente. No entanto, apareceram papéis que não eram esperados, mas que surgiram em alguns momentos, os quais serão explicitados a seguir.

\subsection{Papéis do Aluno}

\subsubsection{Papéis esperados}

Nas interações presenciais e virtuais, o papel do aluno apareceu de diversas formas, dentre elas a de questionar os colegas e o professor-tutor, levantando perguntas acerca do que estava sendo discutido, e a de explicar para os colegas o conteúdo do curso, colaborando com o pensamento dos demais. Outros papéis que apareceram foram o de perguntar para esclarecer dúvidas e o de relatar acontecimentos.

O papel do aluno, no que concerne a relatar acontecimentos, está relacionado à avaliação. Em diversos momentos presenciais, o aluno avaliou pontos positivos e negativos das ações dos colegas, das professoras-tutoras e das disciplinas vigentes e anteriores, o que contribuiu para melhorar o andamento da disciplina que estava em curso. Os relatos também serviram para que as professoras-tutoras tivessem feedback dos alunos a fim de não repetir ações de outros professores-tutores no que concerne à dinâmica das aulas.

O exemplo abaixo demonstra o papel de relatar acontecimentos, pois os alunos argumentaram que a linguagem entre alunos era mais fácil de entender e que haveria mais interação entre eles do que propriamente com ela (a professora-tutora). Esse relato foi feito porque os alunos acharam os textos muito complexos e que, devido a esse fato, a professora-tutora poderia ajudá-los de uma forma diferente, como é mostrado a seguir ${ }^{6}$ :

Evento 1 (Diário de campo. Disciplina: Língua Portuguesa-Frase, 15/09/2008):

Nas explicações da professora-tutora, uma aluna relatou que uma forma dela ajudar os alunos no bate-papo seria perguntar de forma mais fácil, pois 'os alunos vão entender e discutir melhor, é claro'.

Conforme o evento 1 , os alunos demonstraram dificuldade em entender as perguntas da professora-tutora, por isso a interação entre os alunos foi maior do que propriamente com ela porque cada um entendia a linguagem do outro, ou seja, os alunos consideravam os colegas como colaboradores nas discussões. Conforme Masetto (2000, p. 141), os alunos devem "enxergar seus colegas como colaboradores", o que seria uma mudança fundamental de mentalidade no processo de aprendizagem, conferindo-Ihes um sentido de corresponsabilidade nas trocas comunicativas. Os alunos devem ser capazes de assumir responsabilidades, as consequências de seus atos e ter consciência de seus papéis.

No ambiente virtual, o papel do aluno aparece de outras formas, como o de explicar aos colegas o conteúdo que foi discutido, bem como perguntar dúvidas e questionar os

\footnotetext{
${ }^{6}$ Os relatos estão destacados graficamente para diferenciá-los das citações.
} 
colegas acerca das colocações expostas. Em diversos momentos, os papéis do aluno foram evidenciados, como mostra a tabela 1 :

TABELA 1 - Frequência da Subcategoria - Papéis do Aluno (Papéis esperados)

\begin{tabular}{|c|c|c|c|c|}
\hline Papel do Aluno & $\begin{array}{c}\text { Diário de } \\
\text { Campo }\end{array}$ & $\begin{array}{c}\text { Entre- } \\
\text { vistas }\end{array}$ & $\begin{array}{c}\text { Fó- } \\
\text { runs }\end{array}$ & $\begin{array}{c}\text { Bate- } \\
- \text { papos }\end{array}$ \\
\hline Explicar & 7 & 0 & 26 & 33 \\
\hline Questionar & 7 & 0 & 9 & 8 \\
\hline $\begin{array}{c}\text { Perguntar (tirar } \\
\text { dúvidas) }\end{array}$ & 10 & 0 & 12 & 81 \\
\hline $\begin{array}{c}\text { Relatar aconte- } \\
\text { cimentos }\end{array}$ & 11 & 5 & 1 & 7 \\
\hline
\end{tabular}

FONTE: Elaborado pela própria autora.

As frequências mais acentuadas dizem respeito aos fóruns e bate-papos, uma vez que o segundo fórum era um fórum tira-dúvidas e a regra do fórum era que os alunos se ajudassem entre si, o que fez com que cada aluno perguntasse ao colega e explicasse o que sabia à turma, compartilhando seus conhecimentos com os demais. No papel de questionar, os alunos instigavam os demais com as respostas dadas, pois havia discordâncias entre eles e levantamento de outras questões, as quais não eram somente para tirar dúvidas, mas fazer com que o colega repensasse sua resposta.

Em relação a relatar acontecimentos, observa-se que na ferramenta fórum a frequência foi muito baixa, uma vez que os alunos não tinham um fórum específico para fazer a avaliação da disciplina e a autoavaliação, o que pode ter dificultado o desenvolvimento desse papel na ferramenta explicitada.

A seguir, os papéis não-esperados que o aluno desempenhou.

\subsubsection{Papéis não-esperados}

Dois papéis apareceram e não necessariamente são funções desempenhadas pelos alunos, que foram o de incentivar e o de líder. $\mathrm{Na}$ literatura, o papel de incentivar comumente é atribuído ao professor, uma vez que sua função é de encorajar (ALONSO; ALEGRETTI, 2003) os alunos em cursos online. Em relação à liderança, esse papel pode ou não ser desempenhado pelo aluno (MIRANDA; OSÓRIO, 2008), uma vez que estes autores se referem aos participantes e não a alguém em específico, conforme referenciado no aporte teórico. Já para Palloff e Pratt (2002), a liderança é um dos papéis que o aluno pode assumir com ou sem a responsabilidade adicional de avaliar o trabalho dos colegas. Caso essa avaliação aconteça, o aluno deve ser capaz de instigar o pensamento do colega através de comentários significativos fazendo-o refletir sobre a atividade realizada, o que inclui o uso de uma linguagem não ofensiva, mas a direcionamentos necessários para o crescimento do outro enquanto membro da comunidade. Por sua vez, essa habilidade de escrita estaria inserida nas habilidades pessoais elencados por Borba et al. (2007), Moore e Kearsley (2006) e Palloff e Pratt (2004).

Em alguns momentos, havia alunos que assumiram a liderança, fosse num lembrete de boas vindas ao iniciar a disciplina ou um lembrete para a entrega de uma tarefa. A liderança foi vista também na mobilização da formação de grupos para realizar uma atividade, ou em alguma iniciativa que incluísse a turma como um todo.

No ambiente presencial, em relação ao papel de líder, verifica-se que aparece de diversas formas. Uma delas, quando uma aluna, espontaneamente, passou uma folha para os 
colegas que desejavam a cópia de um material, assim ela fotocopiava para tais alunos. No ambiente virtual, essa mesma aluna, Bian$\mathrm{Ca}^{7}$, enviou uma mensagem a todos desejando boas-vindas, pois os alunos tiveram dois meses de recesso e estavam retornando às aulas. A mensagem demonstrou que a aluna tinha o papel de líder e indiretamente ela deixava claro esse papel, conforme o exemplo a seguir:

Evento 2 (Diário de campo. Disciplina: Língua Portuguesa-Frase, 16/09/2008):

Bianca pergunta para a turma: "vocês viram a mensagem que eu enviei para vocês"?

Conforme anotações do diário de campo, um colega de sala, Lucas, já havia relatado que comumente Bianca agia dessa forma, não sendo a primeira vez que a colega tivera tal atitude, fosse ao início ou no decorrer de uma disciplina. Lucas falou também que Bianca ficava no clímax porque não se aguentava e tinha que mandar mensagens para todos, conforme suas palavras no encontro presencial.

Para Miranda e Osório (2008), a liderança é a capacidade que um indivíduo tem de orientar os demais membros de uma organização ou comunidade no percurso desejado, a fim de atingir um objetivo, mantendo o espaço aberto para debates e reflexões, permitindo manter vivo "[...] os espaços de comunicação, facilitar o acesso aos conteúdos, dinamizar o diálogo entre os participantes, ajudando a partilhar as suas próprias experiências e a construir novos conhecimentos [...]" (MIRANDA; OSÓRIO, 2008, p. 2).

\footnotetext{
7 Para preservar a identidade dos participantes, os nomes são fictícios.
}

A tabela 2 apresenta a frequência dos papéis não-esperados:

TABELA 2 - Frequência da Subcategoria Papéis do Aluno (não-esperados)

\begin{tabular}{|c|c|c|c|c|}
\hline $\begin{array}{c}\text { Papel do } \\
\text { Aluno }\end{array}$ & $\begin{array}{c}\text { Diário de } \\
\text { Campo }\end{array}$ & $\begin{array}{c}\text { Entrevis- } \\
\text { tas }\end{array}$ & Fóruns & $\begin{array}{c}\text { Bate- } \\
\text { papos }\end{array}$ \\
\hline Líder & 6 & 2 & 0 & 4 \\
\hline Incentivar & 3 & 1 & 8 & 6 \\
\hline
\end{tabular}

FONTE: Elaborado pela própria autora.

De acordo com a tabela, os dados só não mostram a ocorrência do líder no fórum, uma vez que, nessa ferramenta, os alunos esperavam os colegas postarem alguma mensagem para iniciar a discussão e gerar outras, o que não aconteceu nos demais tipos de dados.

A seguir, são apresentados os papéis do professor-tutor.

\subsection{Papéis do Professor-Tutor}

\subsubsection{Papéis esperados}

Relacionado ao pensamento de Niskier (1999), percebe-se que o professor-tutor assumiu vários papéis ao mesmo tempo, dentre eles: o de explicar o conteúdo, o que envolvia tirar dúvidas; incentivar; revisar o conteúdo; solicitar a participação dos alunos, bem como pedir para citar as referências das respostas, uma ajuda no decorrer da aula etc.; perguntar e questionar sem fornecer, a priori, a resposta correta. Outros papéis foram o de fornecer pistas e o de abrir as discussões no ambiente virtual com uma breve mensagem acerca do que seria discutido, e por último se fazer presente no AVA. Para Brandão et al. (2005), uma variável importante para fomentar a interação é uma mensagem de abertura ou de início de conversação. 
Em relação ao papel de questionar, o mesmo estava relacionado a instigar o raciocínio dos alunos com perguntas e situações que os levassem a pensar, fazendo com que desenvolvessem o raciocínio crítico, abrindo caminhos para novas interpretações acerca do que estava sendo discutido.

No evento a seguir, alguns papéis do professor-tutor:

Evento 3 (Chat 3 - turma A. Tema: Aspectos Pragmáticos da Frase. Disciplina: Língua Portuguesa-Frase, 01/10/2008):

L.1 LÉIA fala para TODOS: [Professora-tutora] L.2 Agora, vamos falar sobre estatuto informacional [Muda o tópico da discussão]

L.3 LÉIA fala para TODOS:

L.4 Como se define esse aspecto pragmático? [Perguntar]

L. 5 LUCAS fala para TODOS:

L.6 Sim. Agora, que tal exemplos sobre as funcoes ideacional,

L.7 interpessoal e textual?

L.8 LÉIA fala para TODOS:

L. 9 Vamos lá, gente! [Incentiva]

...

L.10 Quem poderia responder a questão do Lucas! [Solicita]

L.11 LÉIA fala para TODOS:

L.12 Definir as três metafunções do Halliday! [Revisa as questões colocadas pelo aluno]

L.13 LÉIA fala para TODOS:

A frase, na função ideacional, é vista como processo cognitivo, mental (expressando nosso conhecimento de mundo)... [Explica o conteúdo]

No evento 3, vários papéis são destacados, uma vez que a professora-tutora modificou o tópico da discussão, deixando claro para os alunos que mudou o questionamento. Em seguida, fez uma pergunta iniciando a discussão. Depois, incentivou os alunos a participarem e pediu que vissem e ajudassem o colega a construir suas próprias ideias acerca do que foi perguntado. Posteriormente, recapitulou as questões colocadas pelo aluno para que os demais não perdessem tempo, voltando ao início da discussão. E por último, explicou uma das respostas. Essas ações da professora-tutora mostraram que ela esteve mediando as questões que os alunos estavam a discutir, não se omitindo e interagindo quando era necessário. A função de mediar pode ou não estar presente nas demais ações (explicar fornecer feedback, solicitar, questionar etc.) do professor-tutor, uma vez que a mediação não acontece de forma isolada. Para Masetto (2000) e Passerino et al. (2007), o professor assume o papel de mediador pedagógico trabalhando em equipe com os alunos e buscando alcançar os mesmos objetivos que eles.

No que se refere a se fazer presente no AVA, esse papel está relacionado à quantidade de mensagens enviadas pelas professoras-tutoras nos fóruns de discussão e nos bate-papos, uma vez que o professor-tutor pode acessar o ambiente e não enviar nenhuma mensagem ao aluno, o que pode passar despercebido nas interações virtuais, pois em alguns AVA, como no caso do AVA utilizado na pesquisa, ainda não é possível visualizar os participantes que estão online. Esse papel de se fazer presente no AVA relaciona-se a fornecer feedback aos alunos, interferir quando algo não vai bem, quando depois de algum tempo as discussões não chegam a um entendimento compartilhado de ideias, e incentivar a participação de todos com a finalidade que as discussões cresçam. 
Para Kenski (2003), a presença é um papel essencial ao professor que atua em ambientes virtuais. Existem CVA que não estão baseadas na presença de um professor, mas em um curso, essa é uma condição fundamental, caso contrário, os membros poderiam se sentir abandonados e desmotivados.

A tabela 3 mostra a frequência dos outros papéis que o professor-tutor assumiu:

TABELA 3 - Frequência da Subcategoria Papéis do Professor-Tutor (esperados)

\begin{tabular}{|c|c|c|c|c|}
\hline $\begin{array}{c}\text { Papel do Profes- } \\
\text { sor-Tutor }\end{array}$ & $\begin{array}{c}\text { Diário } \\
\text { de } \\
\text { Campo }\end{array}$ & $\begin{array}{c}\text { Entrevis- } \\
\text { tas }^{8}\end{array}$ & Fóruns & $\begin{array}{c}\text { Bate- } \\
\text { papos }\end{array}$ \\
\hline Explicar & 9 & - & 8 & 134 \\
\hline Questionar & 3 & - & 1 & 121 \\
\hline $\begin{array}{c}\text { Abrir a dis- } \\
\text { cussão no AVA }\end{array}$ & - & - & 1 & 6 \\
\hline Incentivar & 1 & - & 7 & 68 \\
\hline $\begin{array}{c}\text { Revisar o con- } \\
\text { teúdo }\end{array}$ & 5 & - & 0 & 8 \\
\hline $\begin{array}{c}\text { Se fazer pre- } \\
\text { sente no AVA }\end{array}$ & - & - & 15 & 773 \\
\hline Fornecer pistas & 2 & - & 2 & 8 \\
\hline Solicitar (pedir) & 12 & - & 1 & 25 \\
\hline
\end{tabular}

FONTE: Elaborado pela própria autora.

Pelos dados da tabela, a maior frequência está nos bate-papos conduzidos pela professora-tutora da disciplina de Língua Portuguesa: Frase ${ }^{9}$, pois em todo momento ela interviu, com mensagens de explicação do conteúdo, de incentivo, de questionamentos e solicitação. A maior participação da professora-tutora foi nos bate-papos 2 e 3 . Ao final do bate-papo 2, quando todos os alunos haviam saído da sala, a professora-tutora relatou à pesquisadora: O pessoal anda com muita dificuldade. Tá muito difícil mediar essa discipli-

\footnotetext{
${ }^{8}$ Não houve entrevistas com as professoras-tutoras.

${ }^{9}$ Não houve bate-papo na segunda disciplina - Latim II: Língua e Cultura.
}

na!, Dificuldades acadêmicas! Compreensão da teoria e participação no fórum, chat....

No terceiro bate-papo, a professora-tutora perguntou aos alunos se eles esperariam apenas por suas colocações e não iam interagir com os colegas. Os alunos se pronunciaram dizendo que esperaram uma resposta dela às colocações feitas, pois eles estavam com dúvidas acerca do conteúdo.

Nem todas as mensagens da professora-tutora estão nos papéis elencados na tabela, pois algumas mensagens eram referentes às normas do bate-papo, mensagens repetidas para que os alunos se atentassem para a discussão, mensagens para recepcionar algum aluno que chegasse atrasado ao bate-papo, ou mensagens de despedida ao finalizar a sessão. Embora fossem mensagens que não tinham diretamente relação com os diversos papéis elencados nas tabelas, a professora-tutora mostrou-se atenta às discussões e às colocações dos alunos.

Nos dois fóruns de discussão analisados, poucas mensagens foram direcionadas às professoras-tutoras. Cada uma enviou oito e sete mensagens, respectivamente, referentes às disciplinas Língua Portuguesa: Frase e Latim II: Língua e Cultura. Suas colocações eram somente para parabenizar o que estava escrito ou eram uma intervenção breve sobre algum questionamento equivocado, especificamente no fórum tira-dúvidas da disciplina Latim II. Esse fórum obteve o maior número de participações, o que fez com que os alunos, assim como nos demais fóruns, não se limitassem a uma quantidade exata de mensagens, mas interagissem quantas vezes quisessem e tivessem dúvidas.

Pelas notas do diário de campo e dos bate-papos, observa-se que a intervenção docente se deu mais nesses dois momentos, pois 
os alunos tinham as professoras-tutoras como alguém que estava bem próximo (mesmo que virtualmente, como no caso dos bate-papos), ao mesmo tempo em que eles, aptos a responder as dúvidas que iam surgindo.

Outro papel evidente do professor-tutor na tabela foi o de incentivar no ambiente virtual, pois os alunos se sentiram capazes de colaborar com as discussões síncronas, fazendo-se presentes constantemente e instigados a interagir com os demais alunos.

\subsubsection{Papéis não-esperados}

Um papel do professor-tutor que apareceu nas discussões e que não se caracteriza como um papel esperado é o papel social, que estaria relacionado ao envolvimento, empatia, capacidade de ouvir e acolher os alunos, o que Kenski (2003) denomina papel de pessoa.

$\mathrm{Na}$ pesquisa, esse papel relaciona-se às conversas com os alunos não apenas referentes ao conteúdo do curso, mas assuntos pessoais, conforme foram observados nas aulas presenciais, nos intervalos, no início e no final das sessões de bate-papo. Pelas observações do diário de campo e pelas observações virtuais das duas disciplinas, o papel social se evidenciou na disciplina de Língua Portuguesa: Frase e apareceu de duas formas: formal e informal.

Formal quando a professora-tutora, no primeiro dia de aula presencial, perguntou aos alunos como tinha sido o recesso deles durante os dois meses que tiveram e se eles haviam descansado e estavam dispostos para retornar as atividades letivas. Informal ${ }^{10}$ quando

\footnotetext{
10 hehehehehe, rsrsrsrsrs (onomatopeias); (!! / .....) (pontuação expressiva), (ESTUDEM!!!!!) - uso de letra maiúscula seguido de pontuação expressiva no bate-papo, pedindo que os alunos estudassem e :) (uso de emoticon ao final do bate-papo).
}

a professora-tutora fez algum comentário engraçado para descontrair a turma; quando conversou com as alunas e se referiu a elas por meninas; quando fez uso de onomatopeias, emoticons, letras maiúsculas e pontuação expressiva nos bate-papos, o que caracterizou uma abertura de sua parte ao tratar de assuntos pessoais dos alunos, os quais de certa forma estavam relacionados ao curso. Esse papel não foi atribuído à professora-tutora da disciplina de Latim II: Língua e Cultura, uma vez que as aulas iniciaram diretamente com a exposição do conteúdo e com as dúvidas dos alunos, o que não significa dizer que seja um papel a ser exercido/desempenhado pelo professor que atua em cursos online.

Em relação ao ambiente virtual, ao final de um dos bate-papos, todos os alunos haviam saído da sala e uma aluna relatou para a professora-tutora da disciplina de Língua Portuguesa: Frase que não havia postado as atividades de portfólio porque estava com problemas em casa com seu filho. A professora-tutora ouviu pacientemente toda a história relatada pela aluna naquele momento. Aconselhou, incentivou e pediu que a aluna ficasse tranquila e que tudo era uma fase passageira.

A seguir, um exemplo do papel social da professora-tutora:

Evento 4 (Chat 2 - turma B. Tema: Dualidade da estrutura oracional e centralidade do verbo. Disciplina: Língua Portuguesa-Frase, 01/10/2008):

L.1 LÉIA fala para TODOS:

L.2 Vi que vc não postou as outras atividade!

L. 3 LÉIA fala para TODOS:

L. 4 Vc conseguir fazer isso até amanhã?

L. 5 SOFIA fala para LÉIA:

L. 6 è profa, estou muito sem estímulo 
L.7 LÉIA fala para TODOS:

L. 8 Posso saber o motivo?

L. 9 LÉIA fala para TODOS:

L.10 Não se sinta assim, vc é uma boa aluna! ...

L.11 SOFIA fala para LÉIA:

L.12 profa, não tenho mais objetivos e isso está me preocupando

L.13 LÉIA fala para TODOS:

L.14 Tenha paciência, Sofia!

L. 15 SOFIA fala para LÉIA:

L.16 pois viver sem objetivos, que sentido tem a vida?

L.17 LÉIA fala para TODOS:

L.18 Não diga isso, vc é muito boa!

L.19 SOFIA fala para LÉIA:

L.20 Preciso ouvir isso. Que me faça sentir: ser gente

...

L.21 LÉIA fala para TODOS:

L.22 Sofia, se vc precisar de ajuda para fazer suas atividades pode me

L.23 enviar um e-mail que te ajudo!

L. 24 SOFIA fala para LÉIA:

L.25 Tá bem, professora. Desculpe, por está comentando essas coisas.

L.26 LÉIA fala para TODOS:

L.27 ok! Mas não desista, vc muito boa e merece concluir seu curso!

L. 28 SOFIA fala para LÉIA:

L.29 Mas é como um desabafo.

L.30 LÉIA fala para TODOS:

L.31 Não se preocupe! Isso faz parte da vida!

L.32 LÉIA fala para TODOS:

L.33 Se precisar pode contar! Estamos aqui para nos ajudarmos!

L.34 LÉIA fala para TODOS:

L.35 Boa tarde, Sofia! E não desita, quero ver vc na formatura! Abraços!

A tabela 4 apresenta a frequência do papel social da professora-tutora:

TABELA 4 - Frequência da Subcategoria - Papéis do Professor-Tutor (não- esperados)

\begin{tabular}{|c|c|c|c|c|}
\hline $\begin{array}{c}\text { Papel do } \\
\text { Professor- } \\
\text { Tutor }\end{array}$ & $\begin{array}{c}\text { Diário de } \\
\text { Campo }\end{array}$ & $\begin{array}{c}\text { Entrevis- } \\
\text { tas }\end{array}$ & Fóruns & $\begin{array}{c}\text { Bate- } \\
\text { papos }\end{array}$ \\
\hline Social & 6 & - & 0 & 6 \\
\hline
\end{tabular}

FONTE: Elaborado pela própria autora.

Conforme foi evidenciado, o papel social da professora-tutora apareceu apenas nos momentos síncronos, uma vez que não houve entrevistas com a professora-tutora, e nos fóruns, a discussão seguiu diretamente aos conteúdos. Verifica-se que esse papel não é obrigatório que o professor desempenhe, mas, pelos dados da pesquisa, foi um papel aceito pelos participantes. Diz-se aceito porque os alunos tiveram a liberdade de conversar, de se aproximar presencialmente da professora-tutora e relatar problemas. A seguir, discute-se a similaridade dos papéis entre professor-tutor e alunos.

\subsection{Similaridade de Papéis}

Em alguns momentos, o aluno desempenha papéis similares aos do professor-tutor, como o de explicar, posicionar-se perante as colocações do outro, pedir esclarecimentos que justifiquem uma resposta; fazer perguntas que impliquem aprofundamento de questões; sintetizar as ideias das discussões, e refletir criticamente sobre o processo de ensino-aprendizagem. Algumas vezes os papéis do aluno e do professor-tutor se diferenciam no que diz respeito ao planejamento da dinâmica da aula, na supervisão de atividades 
e na avaliação contínua, que são atribuídos exclusivamente ao papel do professor-tutor, conforme anotações do diário de campo.

Como mostram as tabelas 1, 2, 3 e 4, respectivamente, os papéis similares foram: questionar, explicar e incentivar. No ambiente presencial, a similaridade de papéis apareceu quando o aluno explicou o conteúdo ao colega, lembrou-se das teorias de uma das disciplinas anteriores e refez a pergunta que estava sendo discutida para que a colega pudesse entender a resposta, conforme exemplificado no evento 5. No virtual, em um dos fóruns de discussão, uma aluna explicou o procedimento da tradução de frases da língua latina para a língua portuguesa, disponibilizando a todos uma pesquisa que ela realizou acerca do conteúdo que estava sendo abordado, o que incitou a participação de todos. A aluna forneceu, além da ajuda, a referência bibliográfica ao final de sua mensagem, o que deu margem para os colegas pesquisarem na mesma fonte, bem como tirarem outras dúvidas. Comumente esses papéis são atribuídos ao professor-tutor, visto ser ele aquele que tem o dever de estar à frente de todas as dúvidas dos alunos.

Num mesmo evento, verificam-se a similaridade de papéis:

Evento 5 (Diário de campo. Disciplina: Latim II - Língua e Cultura, 06/10/2008):

Um aluno abriu a discussão explicando a turma à resolução de uma das questões. Uma aluna não entendeu a resposta e faz a pergunta para a professora-tutora. Ela responde a pergunta da aluna, mas o aluno refaz a pergunta da colega para que a professora-tutora respondesse de outra maneira, pois a aluna continuava sem entender.
No evento 5, o aluno iniciou a discussão acerca do material; respondeu ao colega e explicou os passos para a resolução da questão; recapitulou o conteúdo de uma das disciplinas anteriores e refez a pergunta para que a colega pudesse entender a matéria de outra forma, uma vez que ele poderia apenas ter dito a resposta da questão solicitada pela professora-tutora. Em resposta à aluna, o papel da professora-tutora deveria ter sido explicar as diferentes formas que a questão poderia ser respondida, mas ela mostrou apenas uma possibilidade, fazendo com que o aluno que iniciou a discussão refizesse a pergunta para que a professora-tutora respondesse de outra forma.

A seguir, um mapa conceitual ${ }^{11}$ com a síntese dos dados.

\subsection{Mapa Conceitual Sobre os Papéis Encontrados no Curso Investigado}

Como forma de estruturar e resumir os papéis similares desempenhados por professor-tutor e aluno na comunidade investigada, criou-se um mapa conceitual conforme é mostrado na figura seguinte.

\footnotetext{
11 "Estrutura esquemática para representar um conjunto de conceitos imersos numa rede de proposições. [...]. Pode ser entendido como uma representação visual utilizada para partilhar significados, pois explicita como o autor entende as relações entre os conceitos enunciados. O mapa conceitual se apoia fortemente na teoria da aprendizagem significativa de David Ausubel, que menciona como o ser humano organiza o seu conhecimento através de uma hierarquização dos conceitos." (TAVARES, 2007).
} 


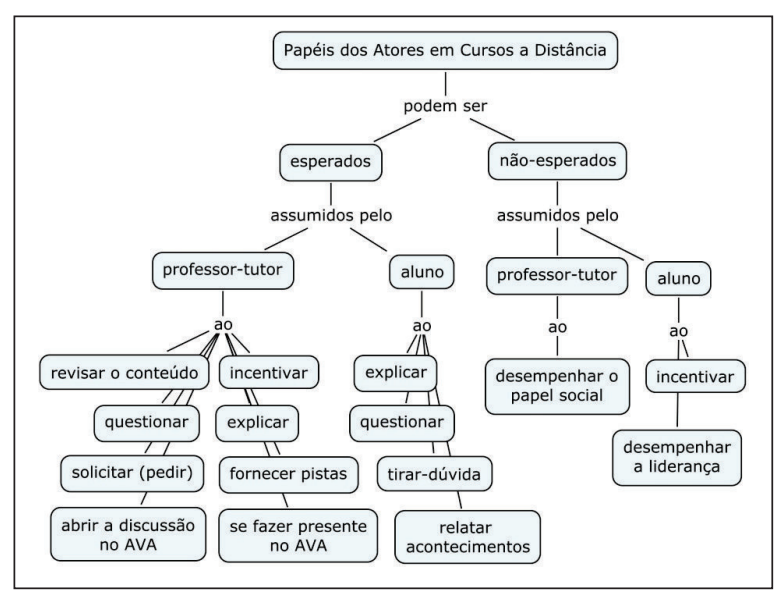

FIGURA 1 - Mapa Conceitual Sobre Papéis dos Atores em Cursos a Distância

FONTE: Elaborado com base na Dissertação de Mestrado (VENTURA, 2009) ${ }^{12}$.

Pelo mapa, os participantes desempenharam uma diversidade de papéis nas trocas comunicativas sendo classificados em esperados e não-esperados. Os papéis esperados que o professor-tutor desempenhou foram o de explicar, questionar, incentivar, abrir a discussão no AVA, revisar o conteúdo, fazer-se presente no AVA, fornecer pistas e solicitar (pedir). Em relação ao papel não-esperado, o professor-tutor assumiu o papel social, considerado fundamental para o desenvolvimento da comunidade, uma vez que a abertura dada aos alunos caracterizou um espaço de confiança, fazendo com que os alunos pudessem se aproximar da professora-tutora ${ }^{13}$ e avaliar todos os momentos, e não apenas aqueles em que tiveram êxito.

Os papéis esperados que os alunos desempenharam estavam relacionados ao de explicar, questionar, tirar dúvidas e relatar acontecimentos. Os papéis dos alunos que não

\footnotetext{
12 Referência completa disponível em Referências, ao final do artigo.

13 Conforme os dados, o papel social foi encontrado apenas na professora-tutora da disciplina Língua Portuguesa: Frase.
}

foram esperados relacionaram-se ao papel de incentivar e ao de líder, propiciando o desenvolvimento da autonomia, a busca por novas descobertas e responsabilidade ao desempenhar determinado papel. Embora a literatura não considere unânime que a liderança seja um papel atribuído ao aluno, na referida pesquisa, esse papel foi desempenhado apenas por ele, daí a classificação de não-esperado.

A seguir, outras considerações.

\section{Considerações Finais}

Discutir a similaridade de papéis entre os atores de um curso a distância requer primeiramente o mapeamento de quais papéis eles efetivamente assumiram. No entanto, nem todos os papéis esperados do professor-tutor e aluno são por eles exercidos, devido a questões didático-pedagógicas e de infra-estrutura, por exemplo, assim como a falta de habilidade pessoal e requisitos tecnológicos, especificados no decorrer do texto. Cada ator precisa (re) conhecer-se em contínuo estado de formação, para lidar com as peculiaridades e potencialidades dos demais participantes, sendo um dos requisitos para o desenvolvimento espontâneo de quaisquer que sejam os papéis.

Ainda que esse estudo não tivesse a pretensão de estabelecer comparações ao mapear os papéis encontrados em diferentes ambientes de ensino e aprendizagem, verificou-se que todos os papéis categorizados na pesquisa foram exercidos tanto no ambiente presencial quanto no ambiente virtual, exceto quando um papel era específico do virtual como abrir a discussão e se fazer presente no AVA, comprovando que não surgiram separadamente (só no presencial e só no virtual), e sim foram complementados quando inicia- 
dos no ambiente presencial, o que viabilizou a criação de vínculos entre os participantes e a formação de uma comunidade de aprendizagem. Daí a importância de se considerar todos os momentos de encontros entre eles, pois presencial e virtual não devem ser vistos como contextos separados e isolados, mas complementares e interdependentes. Porém nem todos os papéis foram encontrados em todos os instrumentos de coleta utilizados, como no caso da entrevista e nos fóruns de discussão.

Para se pensar em novos papéis que ajudem o grupo a crescer enquanto comunidade aprendente, sugere-se ampliar a discussão em três pontos. Primeiro, estender o período de investigação, pois os papéis podem ou não sofrer modificações com o tempo e a intensidade das interações. Segundo, escolher professores-tutores de áreas diferentes do conhecimento (exatas e humanas, por exemplo), o que implicaria ou não na elaboração de estratégias diversificadas de aprendizagem e, por fim, amplificar o referencial teórico e discutir pesquisas desenvolvidas no Brasil e em outros países, o que permitiria outros olhares sobre o objeto de estudo.

Ressalta-se também que os papéis encontrados foram exemplos específicos da comunidade analisada. Em outras comunidades virtuais de aprendizagem formais, não necessariamente aparecerão os mesmos papéis que apareceram nessa pesquisa.

\section{Referências}

ALONSO, M.; ALEGRETTI, S.M.M. Introduzindo a Pesquisa na Formação de Professores a Distância. In: VALENTE, J.A.; PRADO, M.E.B.B.; ALMEIDA, M.E.B. (Org.). Educação a Distância Via Internet. São Paulo: Avercamp, 2003. P. 163-174.

ALVARIÑO, C. A Formação de Professores à Distância Via Internet. In: TEDESCO, C.J.(Org.). Educação e Novas Tecnologias: esperança ou incerteza? São Paulo: Cortez; Buenos Aires: Instituto Internacional de Planeamiento de la Educacion; Brasília: UNESCO, 2004. P. 165-181.

ARREDONDO, S.C. Acción tutorial en los Centros Educativos: formación y práctica. Madrid: Uned, 1998.

BOGDAN, R.C.; BIKLEN, S.K. Investigação Qualitativa em Educação: uma introdução à teoria e aos métodos. Porto: Porto Ed., 1994.

BORBA, M. et al. Educação a Distância Online. Belo Horizonte: Ed. Autêntica, 2007. 
BRANDÃO, M.A.G. et al. Associação Entre a Colaboração/Cooperação e a Conversação em uma Comunidade Virtual de Enfermagem. In: SIMPÓSIO BRASILEIRO DE INFORMÁTICA NA EDUCAÇÃO, 16., 2005, Juiz de Fora. Anais. Porto Alegre: Sociedade Brasileira de Computação, 2005. P. 125-135.

BRYM, R.J. et al. Sociologia: sua bússola para um novo mundo. São Paulo: Thomson Learning, 2006.

CARVALHO, A.B. Os Múltiplos Papéis do Professor em Educação a Distância: uma abordagem centrada na aprendizagem. In: ENCONTRO DE PESQUISA EDUCACIONAL DO NORTE E NORDESTE, 18., 2007, Maceió. Anais. Maceió: UFAL, 2007.

CERNY, R.Z.; LAPA, A.B. The Collective professor in the Perspective of the Professor's job in. In: CONGRESO INTERNACIONAL EDUTEC, 15., 2012, Las Palmas de Gran Canaria. Anais. Las Palmas de Gran Canaria: EDUTEC, 2012.

EMERENCIANO, M.S.J.; SOUSA, C.A.L.; FREITAS, L.G. Ser Presença Como Educador, Professor e Tutor. Revista Colabora, Curitiba, v. 1, n. 1, p. 4-11, ago. 2001.

GIDDENS, A. Sociologia. 4. ed. Porto Alegre: Artmed, 2005.

GONÇALVES, M.I.R. Comunidade Cooperativa de Aprendizagem em Rede. Boletim Técnico do SENAC, Rio de Janeiro, v. 32, n. 2, p. 50-59, maio/ago. 2006.

GUIMARAES, L.S.R. O Aluno e a Sala de Aula Virtual. In: LITTO, F.M.; FORMIGA, M. (Org.). Educação a Distância: o estado da arte. 2. ed. São Paulo: Pearson Education do Brasil, 2012. V. 2, p. 126-133.

HINE, C. Etnografia Virtual. Barcelona: Ed. Luoc, 2004.

KENSKI, V.M. Tecnologias e Ensino Presencial e a Distância. Campinas, SP: Papirus, 2003.

MACHADO, L.D.; MACHADO, E.C. O Papel da Tutoria em Ambientes de EaD. In: CONGRESSO INTERNACIONAL DE EDUCAÇÃO A DISTÂNCIA, 11., 2004, Salvador. Anais. Salvador: ABED, 2004.

MARTINS, O.B. Teoria e Prática Tutorial em Educação a Distância. Revista Educar, Curitiba, v. 1, n. 21, p. 153-171, jan./mar. 2003.

MASETTO, M.T. Mediação Pedagógica e o Uso da Tecnologia. In: MORAN, J.M.; MASETTO, M.T.; BEHRENS, M.A. Novas Tecnologias e Mediação Pedagógica. 10. ed. São Paulo: Papirus, 2000. P. 133-173.

MILL, D. Sobre o Conceito de Polidocência ou Sobre a Natureza do Processo de Trabalho Pedagógico na Educação a Distância. In: MILL, D.; RIBEIRO, L.R.C.; OLIVEIRA, M.R.G. (Org.). Polidocência na 
Educação a Distância: múltiplos enfoques. São Carlos: EdUFScar, 2010. P. 23-40.

MIRANDA, M.S.; OSÓRIO, A.J. Liderança em Comunidades de Prática Online: estratégias e dinâmicas na @rcacomum. In: CONGRESO IBEROAMERICANO DE INFORMÁTICA EDUCATIVA, 9., 2008, Venezuela. Anais do RIBIE. Venezuela: Universidad Metropolitana, 2008.

MOORE, M.G.; KEARSLEY, G. Educação a Distância: uma visão integrada. São Paulo: Thomson Learning, 2006.

MORAN, J.M. Contribuições Para uma Pedagogia da Educação Online. In: SILVA, M. (Org.) Educação Online: teorias, práticas, legislação e formação corporativa. São Paulo: Loyola, 2006. P. 41-52.

MOReirA, H.; CALEffe, L.G. Metodologia da Pesquisa Para o Professor Pesquisador. Rio de Janeiro: DP\&A, 2006.

NISKIER, A. Educação a Distância: a tecnologia da esperança; políticas e estratégias a implantação de um sistema nacional de educação aberta e a distância. São Paulo: Loyola, 1999.

PALLOFF, R.M; PRATT, K. Construindo Comunidades de Aprendizagem no Ciberespaço: estratégias eficientes para a sala de aula online. Porto Alegre: Artmed, 2002.

PALLOFF, R.M; PRATT, K. O Aluno Virtual: um guia para trabalhar com estudantes online. Porto Alegre: Artmed, 2004.

PASSERINO, L.M. et al. Uma Proposta Para Mediação Tecnológica em Espaços Virtuais de Aprendizagem. In: SIMPÓSIO BRASILEIRO DE INFORMÁTICA NA EDUCAÇÃO, 18., 2007, São Paulo. Anais. São Paulo: Universidade Presbiteriana Mackenzie; USP, 2007. P. 238-249.

PRADO, M.E.B.B.; ALMEIDA, M.E.B. Redesenhando Estratégias na Própria Ação: formação do professor a distância em ambiente digital. In: VALENTE, J.A.; PRADO, M.E.B.B.; ALMEIDA, M.E.B. (Org.). Educação a Distância Via Internet. São Paulo: Avercamp, 2003. Cap.3, p. 71-85.

SARMET, M.M. Análise Ergonômica de Tarefas Cognitivas Complexas Mediadas por Aparato Tecnológico: quem é o tutor na educação a distância? Dissertação (Mestrado em Psicologia) - Universidade de Brasília, 2003, Brasília, BR-DF.

SCHILLER, J.; LAPA, A.B.; CERNY, R.Z. Ensinar com as Tecnologias de Informação e Comunicação: retratos da docência. Revista e-curriculum, São Paulo, v. 7, n. 1, p. 1-19, abr. 2011. 
SILVA, J.M.L.; ALVES, L.R.G. Professor e Aluno Online: novos e velhos papéis. In: CONFERÊNCIA INTERNACIONAL DE TECNOLOGIAS DE INFORMAÇÃO E COMUNICAÇÃO NA EDUCAÇÃO, 4., 2005, Braga. Anais. Braga: Universidade do Minho, 2005.

SILVA, K.B.O. Docência na Educação a Distância: um estudo sobre identidade docente em um curso de licenciatura em espanhol. Dissertação (Mestrado em Educação) - Universidade do Estado de Santa Catarina, 2013, Florianópolis, BR-SC.

SOUZA, C.A. et al. Tutoria na Educação a Distância. In: CONGRESSO INTERNACIONAL DE EDUCAÇÃO A DISTÂNCIA, 11., 2004, Salvador. Anais. Salvador: ABED, 2004. P. 115-145.

TAVARES, R. Construindo Mapas Conceituais. Ciências \& Cognição, Rio de Janeiro, v. 12, p. 72-85, 2007.

TORRES, C.C. A Educação a Distância e o Papel do Tutor: contribuições da ergonomia. Tese (Doutorado em Psicologia) - Universidade de Brasília, 2007, Brasília, BR-DF.

VENTURA, P. P. B. Comunidades de Aprendizagem em Cursos a Distância: Investigando as Relações Sociais em Ambientes Virtuais. Dissertação (Mestrado em Educação). Universidade Federal do Ceará, Fortaleza, 2009. Disponível em: http://www.tede.ufc.br/tde_busca/processaPesquisa. php?pesqExecutada=1\&id=2686. Acesso em: 31 mai. 2015. 